\title{
CONSUMER DURABLES AND THE BUSINESS \\ CYCLE
}

Emanuel R. Leão

Pedro R. Leão

Setembro 2008

WP $n=2008 / 69$

DOCUMENTO DE TRABALHO

WORKI NG PAPER 
Emanuel R. Leão ${ }^{1}$

Pedro R. Leão ${ }^{2}$

WP n 2008/69

Setembro de 2008

Abstract

1. INTRODUCTION

2. THE MODEL

3. THE TYPICAL FIRM'S BEHAVIOUR

4. THE TYPICAL HOUSEHOLD'S BEHAVIOUR

5. THE MARKET CLEARING CONDITIONS

6.THE COMPETITIVE EQUILIBRIUM

7. CALIBRATION

9. CONCLUSION

REFERENCES

ANNEXES

\footnotetext{
${ }^{1}$ Departament of Economics, Instituto Superior de Ciências do Trabalho e da Empresa and Dinâmia Centro de Estudos sobre a Mudança Socioeconómica, Avenida das Forças Armadas, 1649-026 Lisboa, Portugal, Phone: 00351217903236, Fax: 00351217903933 - E-mail: emanuel.leao@iscte.pt;

2 Department of Economics, Instituto Superior de Economia e Gestão, Technical University of Lisbon and UECE, Rua Miguel Lupi, № 20, 1200 Lisboa, Portugal - E-mail: pleao@iseg.utl.pt.
} 


\section{Consumer Durables and the Business Cycle}

\section{Abstract}

In this paper, we examine the effect of improving the quality of the consumer durables on the general equilibrium of a perfectly competitive economy. Our most interesting finding is that when such an improvement occurs, the percentage response of the labour supply is higher than the percentage response of real output. This is interesting because one of the main shortcomings of standard Real Business Cycle models is that they tend to generate a response of work hours much weaker than the response of real output.

Keywords: dynamic general equilibrium, business cycles, consumer durables, labour supply.

JEL Classification: E13, E21, E24, E32, E37. 


\section{Introduction}

From Schumpeter to the RBC researchers, many authors have suggested that innovations may be a source of business cycles. This paper asks whether innovations in consumer durables can help explain some of the co-movements we observe during business cycles.

Using a basic intertemporal general equilibrium model with consumer durables, we examine what happens when a conventional positive shock to the production function is accompanied by an improvement in the quality of the consumer durables produced.

We build a model where there is only one homogeneous good which we denote real output. There are three possible uses for this output: it can be consumed as a non-durable, it can be used to increase the stock of consumer durables or it can be used for investment (i.e. used to increase the capital stock). Since we only have one homogeneous good, to model the increase in the quality of the consumer durables, we use the reasoning which follows. To improve the characteristics of the consumer durable maintaining the ability of the consumer to enjoy these characteristics is equivalent to maintaining the characteristics of the consumer durable and increasing the ability of the consumer to enjoy these characteristics. This is what we do: we give a positive shock to a parameter of the utility function that influences the value of the stock of consumer durables. The most interesting result that we obtained in the impulse response experiment was a response of labour effort (as a percentage deviation from the steady-state) which was stronger than the response of output.

\section{The model}

This is a closed economy model with no government. There are $\mathrm{H}$ homogeneous households and $\mathrm{F}$ homogeneous firms. There is only one homogeneous good produced in this economy. There are three possible uses for this output: it can be consumed as a non-durable, it can be used to increase the stock of consumer durables or it can be used for investment (i.e. used to increase the capital stock).

We next examine the typical household's preferences, the technology available in the economy (production function and capital accumulation equation), the resource constraints that exist in a given period and the market structure.

Let us start by describing the preferences of the typical household. The typical household maximizes the discounted sum of utilities from now till the end of time. Utility in period $t$ is given by 
$U\left(c_{t}, S_{t}, \ell_{t}\right)=u\left(c_{t}\right)+\theta_{t} v\left(S_{t}\right)+h\left(\ell_{t}\right)$

where $c_{t}$ is consumption of non-durables, $\theta_{t}$ is a parameter, $S_{t}$ is the stock of consumer durables in possession of the household and $\ell_{t}$ is leisure. The function $U(., .,$.$) has the usual properties.$

The per-period rate of depreciation of the stock of consumer durables is supposed to be constant and is denoted $\delta_{s}$ with $0<\delta_{s}<1$. The expenditure on consumer durables made by the household in period $t$ is given by

$$
d_{t}=S_{t}-\left(1-\delta_{s}\right) S_{t-1}
$$

Let us now describe the technology available in the economy: production function and capital accumulation equation. Each firm's production function is described by

$$
y_{t}=A_{t} F\left(k_{t}, n_{t}^{d}\right)
$$

where $y_{t}$ is the physical output of the firm, $A_{t}$ is a technological parameter, $k_{t}$ is the firm's capital stock and $n_{t}^{d}$ is the firm's labour demand.

Capital accumulation is described by

$k_{t+1}=(1-\delta) k_{t}+i_{t}$

where $i_{t}$ is investment in period $\mathrm{t}$ and $\delta$ is the per-period rate of depreciation of the capital stock which is assumed to be constant and belonging to the closed interval $[0,1]$.

The resource constraints are as follows. Each firm starts period $t$ with a stock of capital $k_{t}$ which is pre-determined [ which was determined at $(t-1)]$.In other words, the capital stock that will enter the production function in period $t$ cannot be changed by decisions taken during period $t$.

Each household starts period $t$ with a stock of consumer durables which is the one it held at the beginning of the previous period minus the depreciation which occurred during that period, i.e., the household starts period $t$ with the amount $\left(1-\delta_{s}\right) S_{t}$. If the household wants to enjoy an amount of consumer durables higher than this in period $t$, it must spend some of its income buying consumer durables in period $t$.

Each household has an endowment of time per period which is normalized to one by an appropriate choice of units. This amount of time can be used to work or to rest. Therefore, we can write

$$
n_{t}^{s}+\ell_{t}=1
$$

where $n_{t}^{s}$ is the household's supply of labour during $t$.

Let us now describe the market structure. There are four markets: the goods market, the labour market, the bonds market and the shares 
market. $H$ and $F$ are assumed to be large enough to guarantee that all agents are price-takers. Prices are perfectly flexible and adjust so as to clear all markets in every period. There are three prices in this model: the real wage, the real interest rate and the price of shares in real terms. All these prices are measured in units of output. We can think of these three prices as adjusting to clear the labour market, the bonds market and the shares market, respectively. If these three markets are in equilibrium, then (by Walras Law), the goods market is also in equilibrium.

\section{The typical firm's behaviour}

Each firm $\mathrm{f}(f=1,2, \ldots, F)$ maximizes the Present Value of its Assets (PVA), i.e., the expected discounted value of its stream of present and future dividends. Therefore, the typical firm's optimization problem is:

$$
\begin{aligned}
& \underset{n_{t}^{d}, k_{t+i}}{\operatorname{Max}} P V A=E_{0}\left[\sum_{t=0}^{t=\infty} \frac{1}{1+r_{0, t+1}} \pi_{t}^{f}\right] \\
& \text { with } \pi_{t}^{f}=A_{t} F\left(k_{t}, n_{t}^{d}\right)-w_{t} n_{t}^{d}-\left[k_{t+1}-(1-\delta) k_{t}\right]
\end{aligned}
$$

where $w_{t}$ is the real wage. Given the economic environment we are working with, we think it is appropriate to assume that:

$$
\left(1+r_{0, t+1}\right)=\left(1+r_{0}\right)\left(1+r_{1}\right)\left(1+r_{2}\right) \ldots\left(1+r_{t}\right) \text { for } \mathrm{t}=0,1,2, \ldots
$$

There is also an initial condition for the capital stock, the standard transversality condition for the capital stock and non-negativity constraints. The profits earned by each firm are then distributed to households in the form of dividends.

\section{The typical household's behaviour}

The typical household faces the following sequence of budget constraints

$$
\begin{aligned}
& w_{t} n_{t}^{s}+\sum_{f=1}^{f=F} z_{t}^{f} \pi_{t}^{f}+\sum_{f=1}^{f=F} z_{t}^{f} q_{t}^{f}+\frac{b_{t+1}}{1+r_{t}}=c_{t}+\left[S_{t}-\left(1-\delta_{s}\right) S_{t-1}\right]+b_{t}+ \\
& \sum_{f=1}^{f=F} z_{t+1}^{f} q_{t}^{f}
\end{aligned}
$$

$$
\text { for } \mathrm{t}=0,1,2,3, \ldots
$$

Let us examine these budget constraints in detail. The way bonds work in this model is as follows. In a given period (period t, for example), the household can either sell bonds to other households $\left(b_{t+1}>0\right)$ or buy bonds from other households $\left(b_{t+1}<0\right)$. If it sells one bond at the beginning of period $t$, it receives $\frac{1}{1+r_{t}}$ units of output at the beginning of period $t\left[r_{t}\right.$ is the real interest rate between the beginning of period 
$\mathrm{t}$ and the beginning of period $(\mathrm{t}+1)$, measured in units of output], and it shall have to pay $\frac{1}{1+r_{t}}\left(1+r_{t}\right)=1 \quad$ units of output at the beginning of period $(\mathrm{t}+1)$. Therefore, if at the beginning of period $t$ the household sells $b_{t+1}$ bonds, it receives $b_{t+1} \frac{1}{1+r_{t}} \quad$ units of output at the beginning of period $t$ and it will have to pay $b_{t+1} \frac{1}{1+r_{t}}\left(1+r_{t}\right)=b_{t+1}$ units of output at the beginning of period $(t+1)$.

The way shares work in this model is as follows. $q_{t}^{f}$ is the price, measured in units of output, that the household would have to pay to buy $100 \%$ of firm $\mathrm{f}$ at the beginning of period t. $z_{t}^{f}$ is the percentage of firm $\mathrm{f}$ (i.e. the share of firm $\mathrm{f}$ ) that the household bought at the beginning of period (t-1) and holds at the beginning of period t. $z_{t+1}^{f}$ is the percentage of firm $f$ that the household buys at the beginning of period t. These percentages are measured as numbers belonging to the closed interval $[0,1]$.

The interpretation of the budget constraint is as follows. $w_{t} n_{t}^{s}$ is the amount that the household receives as wages during period $t$. The term $\sum_{f=1}^{f=F} z_{t}^{f} \pi_{t}^{f}$ denotes the amount of dividends that the household receives during period $t$ in return for the shares of the $\mathrm{F}$ firms that it bought in period $(t-1)$. The term $\sum_{f=1}^{f=F} z_{t}^{f} q_{t}^{f}$ corresponds to the amount the household receives in period $\mathrm{t}$ from selling the shares of the $\mathrm{F}$ firms it had bought in period ( $\mathrm{t}-1)$. Finally, the term $\frac{b_{t+1}}{1+r_{t}}$ is the amount of credit the household obtains during period $t$

In the right-hand side of the constraint, $c_{t}$ is consumption of nondurable goods, $\left[S_{t}-\left(1-\delta_{s}\right) S_{t-1}\right]$ is the expenditure on consumer durables during period $t, b_{t}$ is the amount that the household has to pay to other households because of the credit it obtained in the previous period [period $(t-1)]$ and $\sum_{f=1}^{f=F} z_{t+1}^{f} q_{t_{0}+i}^{f}$ is the household's expenditure on shares of the $\mathrm{F}$ firms during period $t$. Note that in period $\mathrm{t}$ the household sells all the shares of the F firms it had bought in period ( $t-1)$ and then she buys new amounts of shares.

The household is looking into the future and maximizes the present discounted value of lifetime utility subject to the relevant constraints as follows:

$$
\begin{aligned}
& \underset{c_{t}, S_{t}, \ell_{t}, b_{t+1}, z_{t+1}^{f}}{\operatorname{Max}} E_{t_{0}}\left[\sum_{t=0}^{t=\infty} \beta^{t}\left[u\left(c_{t}\right)+\theta_{t} v\left(S_{t}\right)+h\left(\ell_{t}\right)\right]\right] \\
& \text { s.t. } \quad w_{t} n_{t}^{s}+\sum_{f=1}^{f=F} z_{t}^{f} \pi_{t}^{f}+\sum_{f=1}^{f=F} z_{t}^{f} q_{t}^{f}+\frac{b_{t+1}}{1+r_{t}}=c_{t}+\left[S_{t}-\left(1-\delta_{s}\right) S_{t-1}\right]+
\end{aligned}
$$




$$
\begin{aligned}
& b_{t}+\sum_{f=1}^{f=F} z_{t+1}^{f} q_{t}^{f} \\
& n_{t}^{s}+\ell_{t}=1
\end{aligned}
$$

$$
\text { for } \mathrm{t}=0,1,2,3, \ldots
$$

There are also initial conditions on holdings of shares [ assuming market clearing in the shares market in period $(t-1)$, these initial conditions will be $z_{t}^{f}=\frac{1}{H}$ and $s_{t}^{l}=\frac{1}{H}$ ], a standard transversality condition on bond holdings and non-negativity constraints.

\section{The market clearing conditions}

With $\mathrm{H}$ homogeneous households and $\mathrm{F}$ homogeneous firms, the market clearing conditions for period $t$ are:

( i ) Goods market

$$
\begin{gathered}
\sum_{h=1}^{h=H} c_{t}+\sum_{h=1}^{h=H}\left[S_{t}-\left(1-\delta_{s}\right) S_{t-1}\right]+\sum_{f=1}^{f=F} i_{t}=\sum_{f=1}^{f=F} y_{t} \Leftrightarrow \\
\Leftrightarrow H c_{t}+H\left[S_{t}-\left(1-\delta_{s}\right) S_{t-1}\right]+F\left[k_{t+1}-(1-\delta) k_{t}\right]= \\
=F A_{t} F\left(k_{t}, n_{t}^{d}\right)
\end{gathered}
$$

( ii ) Labour Market

$$
\sum_{h=1}^{h=H} n_{t}^{s}=\sum_{f=1}^{f=F} n_{t}^{d} \Leftrightarrow H n_{t}^{s}=F n_{t}^{d} \Leftrightarrow n_{t}^{s}=\frac{F}{H} n_{t}^{d}
$$

( iii ) Credit market

$$
\sum_{h=1}^{h=H} \frac{b_{t+1}}{1+r_{t}}=0 \Leftrightarrow H \frac{b_{t+1}}{1+r_{t}}=0 \Leftrightarrow b_{t+1}=0
$$

(iv ) Shares market

The market clearing condition in the shares market is that each firm should be completely held. In other words: the sum of the shares of each firm $\mathrm{f}$ held by the $\mathrm{H}$ households must be equal to $100 \%$

$$
\sum_{h=1}^{h=H} z_{t+1}^{f}=1 \Leftrightarrow H z_{t+1}^{f}=1 \Leftrightarrow z_{t+1}^{f}=\frac{1}{H}
$$

$\mathrm{f}=1,2,3, \ldots, \mathrm{F}$ 


\section{The competitive equilibrium}

To obtain the competitive equilibrium, we put together in a system the first order conditions of the household's problem, the first-order conditions of the firm's problem, and the market-clearing conditions. If, in addition, we assume that the production function is homogeneous of degree one and define the following new variables

$$
\overline{k_{t}}=\frac{F}{H} k_{t}, \bar{\pi}_{t}^{f}=\frac{F}{H} \pi_{t}^{f}, \bar{q}_{t}^{f}=\frac{F}{H} q_{t}^{f},
$$

then we can write competitive equilibrium under Rational Expectations as:

$$
\begin{gathered}
u^{\prime}\left(c_{t}\right)=\lambda_{t} \\
\theta_{t} v^{\prime}\left(S_{t}\right)+\beta\left(1-\delta_{S}\right) E_{t}\left[\lambda_{t+1}\right]=\lambda_{t} \\
h^{\prime}\left(1-n_{t}^{s}\right)=\lambda_{t} w_{t} \\
\frac{\lambda_{t}}{1+r_{t}}=\beta E_{t}\left[\lambda_{t+1}\right] \\
\lambda_{t} \bar{q}_{t}^{f}=\beta E_{t}\left[\lambda_{t+1}\right]\left(E_{t}\left[\bar{\pi}_{t+1}^{f}\right]+E_{t}\left[\bar{q}_{t+1}^{f}\right]\right) \\
\left.c_{t}-\left(1-\delta_{S}\right) S_{t-1}\right]=A_{t} F\left(\bar{k}_{t}, n_{t}^{s}\right)-\left[\bar{k}_{t+1}-(1-\delta) \bar{k}_{t}\right] \\
A_{t} F_{2}\left(\bar{k}_{t}, n_{t}^{s}\right)=w_{t} \\
1+r_{t}\left[E_{t}\left[A_{t+1}\right] F_{1}\left(\overline{k_{t+1}}, E_{t}\left[n_{t+1}^{s}\right]\right)+(1-\delta)\right]
\end{gathered}
$$




$$
\begin{gathered}
b_{t+1}=0 \\
z_{t+1}^{f}=\frac{1}{H} \\
\overline{\pi_{t}^{f}}=A_{t} F\left(\overline{k_{t}}, n_{t}^{s}\right)-w_{t} n_{t}^{s}-\left[\overline{k_{t+1}}-(1-\delta) \overline{k_{t}}\right]
\end{gathered}
$$

The last equation is the definition of profits of firm $\mathrm{f}$ multiplied on both sides by $\frac{F}{H}$. We have two exogenous variables $\left(A_{t}\right.$ and $\left.\theta_{t}\right)$ and twelve endogenous variables: $c_{t}, S_{t}, n_{t}^{s}, \lambda_{t},, w_{t}, r_{t}, \bar{q}_{t}^{f}, \bar{\pi}_{t}^{f}, b_{t+1}, \overline{k_{t}}, n_{t}^{d}$ and $z_{t+1}^{f}$.

The specific utility and production functions used in the simulations below were

$$
A_{t} F\left(k_{t}, n_{t}^{d}\right)=A_{t}\left(k_{t}\right)^{1-\alpha}\left(n_{t}^{d}\right)^{\alpha}
$$

and

$$
U\left(c_{t}, S_{t}, \ell_{t}\right)=u\left(c_{t}\right)+\theta_{t} v\left(S_{t}\right)+h\left(\ell_{t}\right)=\ln c_{t}+\theta_{t} \ln S_{t}+\phi \ln \ell_{t}
$$

\section{Calibration}

To study the dynamic properties of the model, we first log-linearize each of the equations in the above system around the steady state values of the variables. What we obtain is a linear system where instead of each variable appears the percentage deviation of that variable from its steady-state value [for example, instead of $c_{t}$ we have $\hat{c}_{t}=\ln \left(\frac{c_{t}}{c}\right)$ where $c$ is the steady-state value of $c_{t}$ ]. The log-linearized system was then calibrated. Let us go through the details of this calibration. With the specific utility function we are using we obtain

\begin{tabular}{|l|l|}
\hline Elasticity of the MU of c with respect to c & -1 \\
\hline Elasticity of the MU of leisure with respect to leisure & -1 \\
\hline
\end{tabular}

where MU denotes "Marginal Utility". From the USA data, we obtain 


\begin{tabular}{|l|l|l|}
\hline & value & source \\
\hline Investment share of output in the steady-state $(i / y)$ & 0.167 & Barro (1994) \\
\hline Expenditure on consumer durables as \% of output in s.s. & 0.076 & Barro $(1994)$ \\
\hline Labour's share in the steady-state $(\alpha)$ & 0.58 & King et al. $(1988)$ \\
\hline Labour supply in the steady-state $\left(n^{s}\right)$ & 0.2 & King et al. $(1988)$ \\
\hline Rate of depreciation of the consumer durables $\left(\delta_{S}\right)$ & 0.0506 & Bernanke $(1985)$ \\
\hline Real interest rate in the steady-state $(r)$ & 0.00985 & Barro (1994) \\
\hline
\end{tabular}

As usual we take the post-war average as representing the steadystate value. Note that broad investment has been split into firm's investment and expenditure in consumer durables. The last two values in the table are per-quarter values.

The values in the preceding table imply

\begin{tabular}{|l|l|}
\hline & value \\
\hline consumption share of output $(c / y)$ & 0.757 \\
\hline household's intertemporal discount factor $(\beta)$ & 0.99 \\
\hline parameter $\theta$ & 0.11923 \\
\hline per-quarter rate of depreciation of the capital stock $(\delta)$ & 0.006667 \\
\hline
\end{tabular}

The value for $\delta$ is a per-quarter value.

Using the specific production and utility functions mentioned above and some of the values in the tables above, we obtain the following elasticities (evaluated at the steady-state):

\begin{tabular}{|l|l|}
\hline & value \\
\hline Elasticity of the MU of S with respect to $\theta$ & 0.06 \\
\hline Elasticity of the MU of S with respect to S & -0.06 \\
\hline Elasticity of the MU of S with respect to $\lambda$ & 0.94 \\
\hline Elasticity of the MPN with respect to capital & 0.42 \\
\hline Elasticity of the MPN with respect to labour & -0.42 \\
\hline Elasticity of the GMPK with respect to the technological parameter & 0.017 \\
\hline Elasticity of the GMPK with respect to capital & -0.0096 \\
\hline Elasticity of the GMPK with respect to labour & 0.0096 \\
\hline
\end{tabular}

\section{Response of the model to exogenous shocks}

The response of the log-linearized model to exogenous shocks can be obtained using the King, Plosser and Rebelo (1988) method, which is based on Blanchard and Khan (1980).

We performed the following impulse response experiment. Let us suppose that $t_{0}=2$. To do the impulse response experiment we proceeded as follows:

( $\mathrm{i}$ ) Assume that in $t=1$ the economy is in its steady-state with $\hat{A}_{1}=0$ and $\hat{\theta}_{1}=0$; 
( ii ) Assume that at $t=2$, there is a simultaneous shock in $\hat{A}_{t}$ and $\hat{\theta}_{t}$ so that $\hat{A}_{s}=0.001$ and $\hat{\theta}_{s}=0.00001$ for $s=2,3,4, \ldots$ Note this means that the shocks are permanent.

( iii ) Use the values from ( ii) and the Blanchard and Khan algorithm to obtain the expected path that the 'percentage deviation from the steady state' of each variable will take from now until some point in the future ( 20 quarters ahead, for example ). The results are plotted in graphics 1 to 8 .

Note that the response of the labour supply is stronger than the response of real output (see figures 1 and 2). This is especially interesting because one of the main shortcomings of RBC models is that they tend to generate work hours much less volatile than real output.

When an exogenous positive shock occurs in $\theta_{t}$, the change in the relative weights attached to the different components of the utility funcion creates an incentive to increase the stock of consumer durables (figure 8) at the expense of less non-durable consumption (figure 3) and/or less leisure (i.e. more work effort) . This helps explain the strong response of the labour supply (figure 2).

\section{Conclusion}

We have built a dynamic general equilibrium model with both durable and non-durable consumer goods. We have devised a way of modelling an increase in the quality of the consumer durables and have examined its effect on the behaviour of the endogenous variables of model. Our simulation experiments yielded a very interesting result: a response of the labour supply which is stronger than the response of real output. This is interesting because one of the main problems of Real Business Cycle models is that they tend to generate a response of the labour supply much weaker than the response of real output.

The results we obtained suggest that combining shocks to the production technology with other types of innovations may help replicate those stylized facts that production technology shocks alone cannot deliver. 


\section{References}

[1] Baxter, M. (1996). Are consumer durables important for business cycles?. The Review of Economics and Statistics 78: 147-155.

[2] Blanchard, O. and Khan, C. (1980). The solution of linear difference models under rational expectations. Econometrica 48: 1305-1311.

[3] Cook, S. (1999). Cyclicality and durability: evidence from the U.S. consumer's expenditure. Journal of Applied Economics 2: 299-310.

[4] Hansen, G. 1985. Indivisible labor and the business cycle. Journal of Monetary Economics 56: 309-327.

[5] King, R., Plosser, C. and Rebelo, S. (1988). Production, growth and business cycles: I. The basic neoclassical model. Journal of Monetary Economics 21: 195-232.

[6] Kydland, F. and Prescott, E. (1982). Time to build and aggregate fluctuations. Econometrica 50: 1345-1370.

[7] Kydland, F. and Prescott, E. 1990. Business cycles: real facts and a monetary myth. Quarterly Review. Federal Reserve Bank of Minneapolis, Spring.

[8] Long, J. and Plosser, C. (1983). Real Business Cycles. Journal of Political Economy 91: 39-69. 

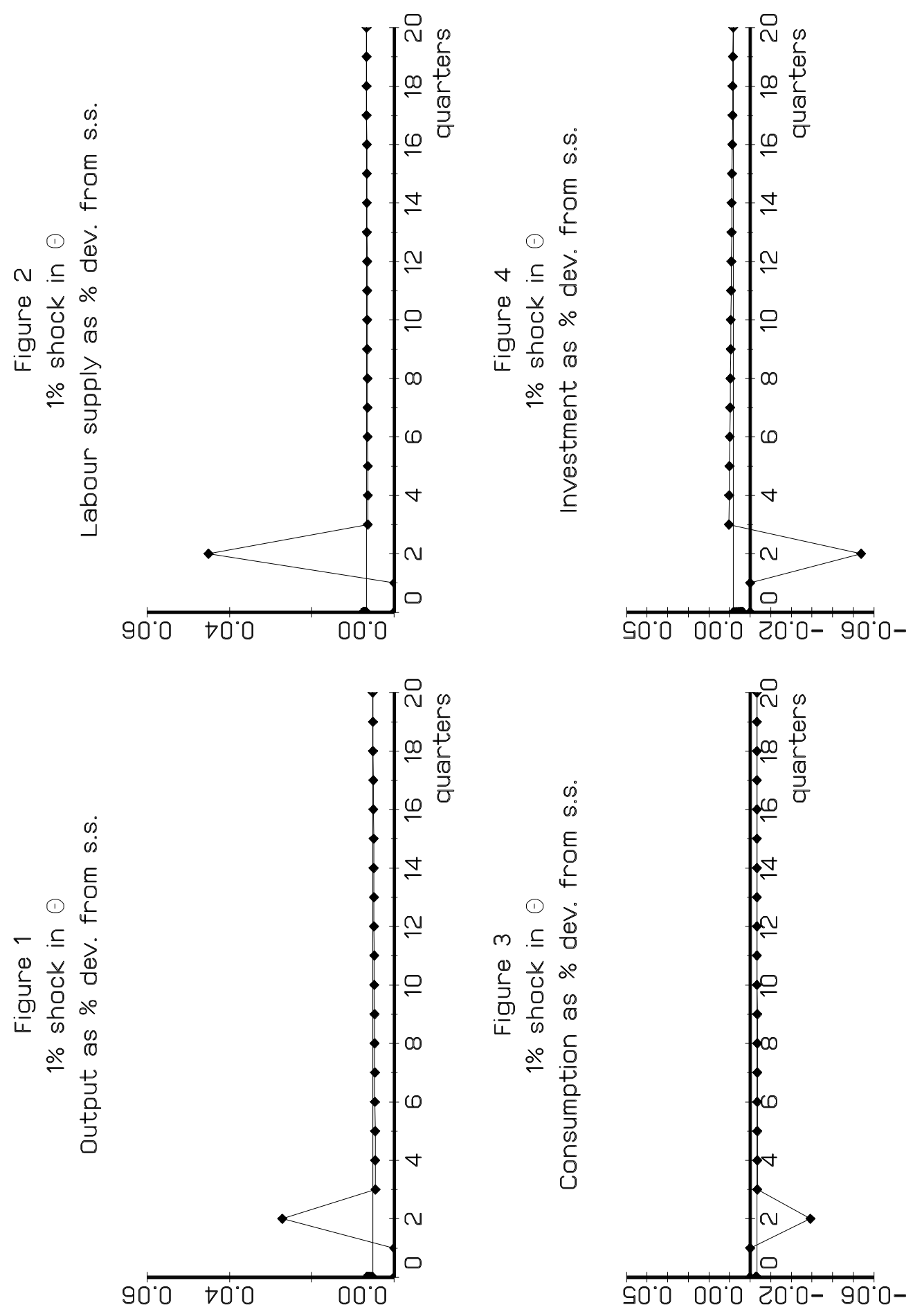

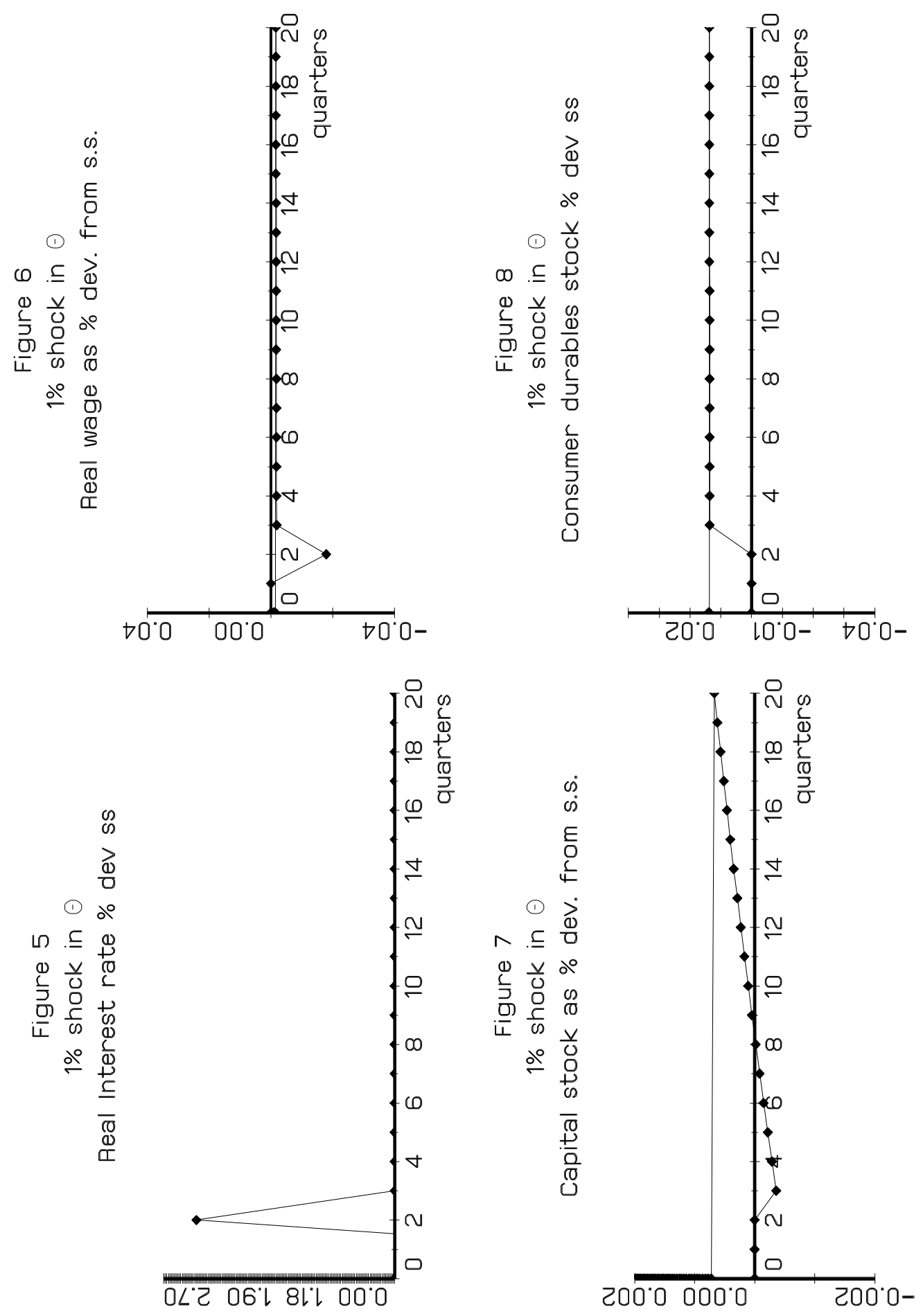